\title{
Preparation of hydroxyapatite ceramic through centrifugal casting process using ultra-fine spherical particles as precursor and its decomposition at high temperatures
}

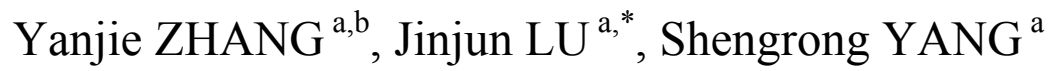 \\ ${ }^{a}$ State Key Laboratory of Solid Lubrication, Lanzhou Institute of Chemical Physics, \\ Chinese Academy of Sciences, Lanzhou 730000, China \\ ${ }^{b}$ Graduate School of the Chinese Academy of Sciences, Beijing 100039, China \\ Received April 13, 2011; Accepted November 15, 2011 \\ (C) The Author(s) 2012. This article is published with open access at Springerlink.com
}

\begin{abstract}
Ultra-fine hydroxyapatite (HAp) powder with a diameter of about $10 \mathrm{~nm}$ was used as precursor for preparation of HAp ceramic. The precursor hydroxyapatite was single phase and highly crystallized without any additional thermal treatment. Highly densified HAp ceramic was fabricated through centrifugal infiltration casting (CIC), followed by pressureless sintering. The relative densities of compacts prepared at $1100^{\circ} \mathrm{C}$ and $1200^{\circ} \mathrm{C}$ were $77.8 \%$ and $94.1 \%$, respectively. SEM micrographs of $\mathrm{HAp}$ ceramic sintered at $1100^{\circ} \mathrm{C}$ showed a porous microstructure with a grain size of $1 \mu \mathrm{m}$. HAp ceramic fabricated at $1200^{\circ} \mathrm{C}$ revealed a dense microstructure with nano-sized spherical $\alpha$-TCP distributed at grain boundaries and triple points. The mechanism of decomposition from HAp to $\alpha$-TCP at $1200^{\circ} \mathrm{C}$ was discussed on the basis of SEM, XRD and FTIR results.
\end{abstract}

Key words: hydroxyapatite; bioceramics; Centrifugal Infiltration Casting; pressureless sintering

\section{Introduction}

Hydroxyapatite (HAp) is a bioactive ceramic with a crystal structure similar to the native bone and teeth minerals. Ceramic hydroxyapatites are widely used in biomedical applications because of their high biocompatibility and forming bonds with living tissues $[1,2]$. Despite its high bioactivity, HAp is limited in applications due to the poor mechanical strength.

\footnotetext{
* Corresponding author.

E-mail: jjlu@1zb.ac.cn

Tel: +86-931-4968198; Fax: +86-931- 4968198.
}

Hence highly densified HAp compact has been investigated for possible application as load-bearing implants. High-density ceramics of HAp are currently prepared by pressure-assisted sintering [3-5]. The morphology and size of HAp powder influence the quality of the ceramic material. There are several different synthesis methods used to generate HAp such as chemical precipitation [6], hydrothermal [7-9], sol-gel [5,10,11], and mechanochemical methods $[12,13]$. The chemical precipitation approach has been chosen because it will likely generate the desired stoichiometry, crystalline phase and grain size at low temperature.

Green pellets of HAp were obtained by isostatic 


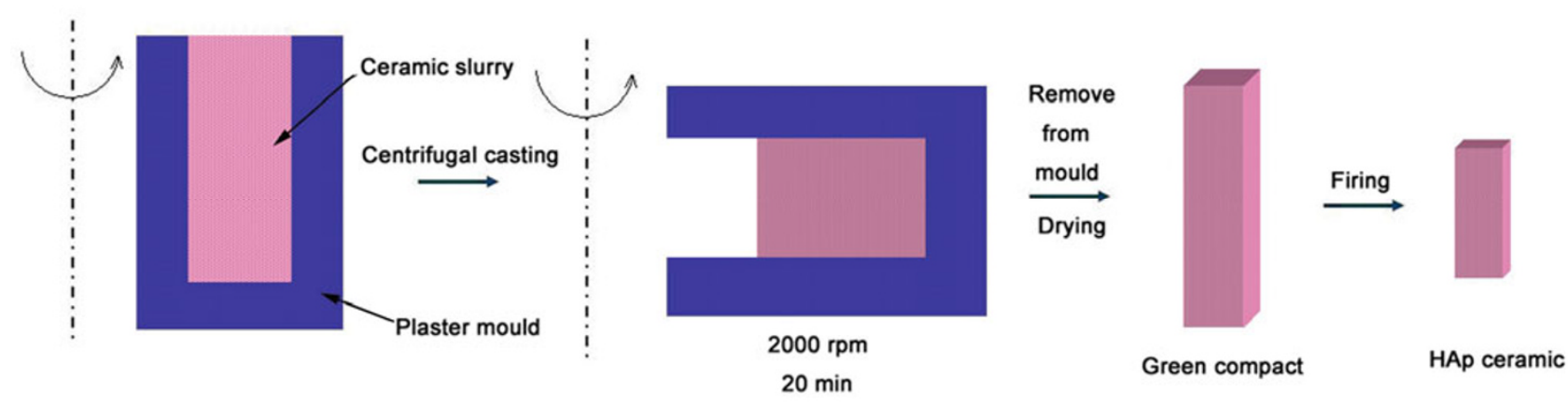

Fig. 1 Schematic illustration of centrifugal casting process

pressing and followed by pressure-assisted sintering process. The HAp ceramics prepared by this process exhibited a dense microstructure and excellent bending strength. It was also reported that the relative density of pressureless sintered HAp could not be higher than $70 \%$ of the theoretical density [3]. However, the drawback of the pressure-assisted sintering process lies in the difficulty in preparing HAp components with complex shapes.

Centrifugal infiltration casting (CIC) is derived from centrifugal casting, which is also a powerful colloidal processing for massive production of ceramic parts with complex shapes. The two molding processes are different in removing solvent from slurries. In the centrifugal casting process, the supernatant is poured off from steel moulds after centrifugation, which will cause possible mass and phase segregation during the consolidation stage $[14,15]$. While in the centrifugal infiltration casting process, the solvent is equably infiltrated in the plaster moulds under a high-speed centrifugation. Therefore the centrifugal infiltration casting process enables to obtain green compacts with a uniform microstructure.

The decomposition of HAp results in changes of mechanical and physicochemical properties of the final materials. Thus, the thermal stability of hydroxyapatite has been widely investigated in the past years, for example, the thermal stability of HAp during hot pressing and pressureless sintering by FTIR and XRD analysis [16] and the properties of porous hydroxyapatite bioceramic produced by the annealing of bovine bone [17].

In the present study, highly densified HAp ceramics were prepared by CIC process and pressureless sintering using ultra-fine HAp particles as precursor. The decomposition mechanism of HAp ceramic was also studied by SEM, XRD and FTIR analysis.

\section{Experimental procedure}

\subsection{Synthesis of ultra-fine HAp powders}

Calcium nitrate $\left(\mathrm{Ca}\left(\mathrm{NO}_{3}\right)_{2} \cdot 4 \mathrm{H}_{2} \mathrm{O}\right)$, diammonium hydrogen phosphate $\left(\left(\mathrm{NH}_{4}\right)_{2} \mathrm{HPO}_{4}\right)$ and ammonium hydroxide $\left(\mathrm{NH}_{4} \mathrm{OH}\right)$ (all analytical grade) were used as reactants. To precipitate $\mathrm{HAp}, 0.5 \mathrm{M}\left(\mathrm{NH}_{4}\right)_{2} \mathrm{HPO}_{4}$ in deionized water was added to $0.5 \mathrm{M}\left(\mathrm{Ca}\left(\mathrm{NO}_{3}\right)_{2} \cdot 4 \mathrm{H}_{2} \mathrm{O}\right)$ in ethanol with vigorous stirring. The $\mathrm{pH}$ of these precursor solutions was adjusted to $10 \sim 11$ by the addition of concentrated $\mathrm{NH}_{4} \mathrm{OH}$. After reaction for $1 \mathrm{~h}$ at $40^{\circ} \mathrm{C}$, the product was kept inside an oven at $30^{\circ} \mathrm{C}$ overnight. Then it was washed three times by water and filtered by centrifuging.

\subsection{Preparation of HAp ceramics}

Slurries with $14 \%$ solid loading were obtained by the filtered ultra-fine HAp powders with $20 \mathrm{ml}$ ethanol through ultrasonic treatment, then consolidated by a high-speed centrifugal machine at $2000 \mathrm{rpm}$ for $20 \mathrm{~min}$ in plaster moulds. After centrifugation, green compacts $\left(42 \times 9 \times 6 \mathrm{~mm}^{3}\right)$ were obtained and dried at room temperature in open air (relative humidity of $40 \%-50 \%$ ) for five days. The whole process was shown in Fig. 1. Finally, those green compacts were sintered for $4 \mathrm{~h}$ in air at $1100^{\circ} \mathrm{C}$ and $1200^{\circ} \mathrm{C}$, respectively.

\subsection{Characterization}

The density of the sintered sample was measured by the Archimedes method. The relative densities of HAp ceramics were obtained using the measured densities over their theoretical density $\left(3.16 \mathrm{~g} / \mathrm{cm}^{3}\right)$. Phase compositions of the ultra-fine HAp powders and the sintered sample were examined by X-ray diffraction (XRD) with $\mathrm{Cu} \mathrm{K \alpha}$ radiation $(\lambda=1.5418 \AA)$. The diffractometer (X'Pert PRO, Philips) was operated at 
$40 \mathrm{kV}$ and $30 \mathrm{~mA}$ at a $2 \theta$ range of $20^{\circ}-70^{\circ}$ employing a step size of 0.0170 and a $29.8450 \mathrm{~s}$ exposure. The products were also characterized by Fourier transform-infrared spectroscopy (FT-IR, IFS 66V/S FTIR, Bruker) in the range of $4000 \mathrm{~cm}^{-1}-400 \mathrm{~cm}^{-1}$. The elemental analysis was conducted by ICP-AES (IRIS Advantage ER/S). The morphology and grain size of the synthesized powders were observed by transmission electron microscopy (TEM, H-600, Hitachi). Surface morphology was observed by scanning electron microscopy (SEM, JSM5600LV, JEOL) on the surface and cross section of the sintered sample.
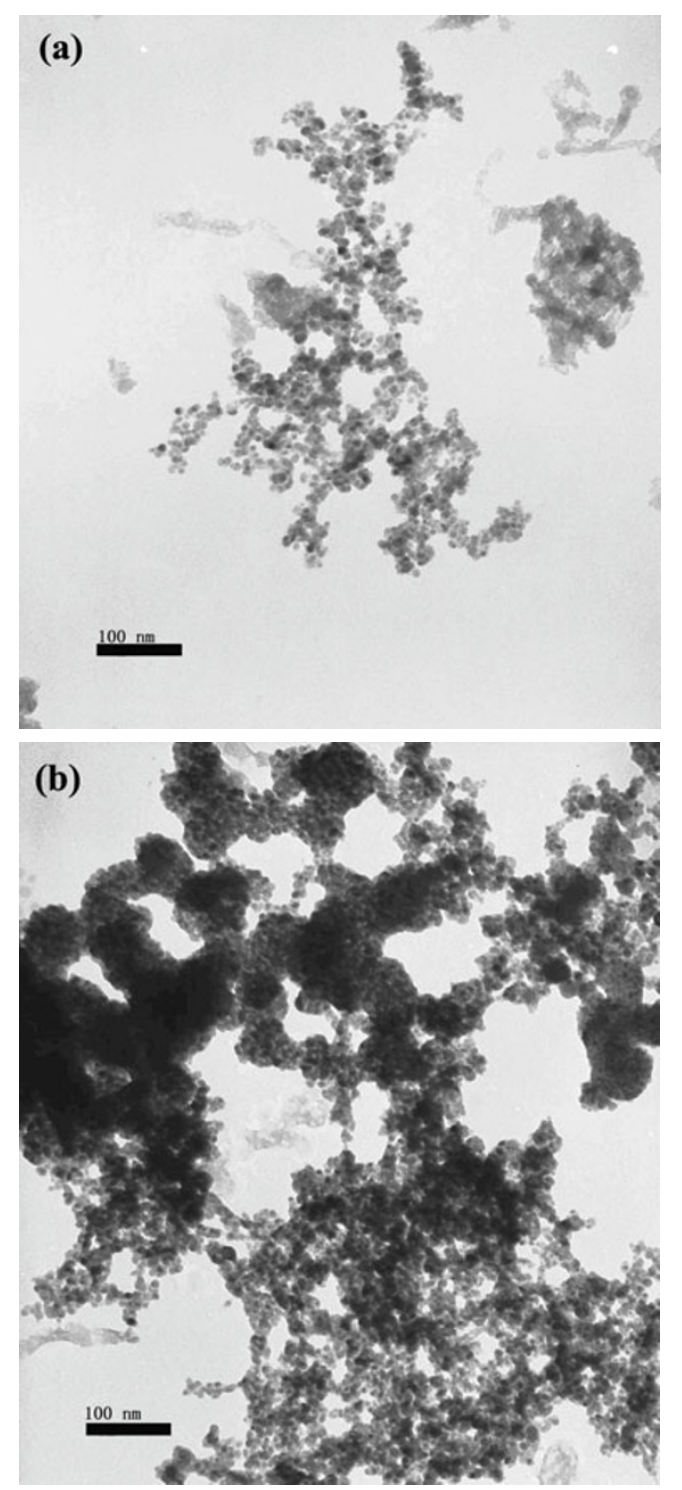

Fig. 2 TEM micrographs of ultra-fine HAp particles: (a) ultra-fine crystal and (b) spherical aggregation self-aligned by ultra-fine particles

\section{Results and discussion}

\subsection{Ultra-fine HAp particles}

The ultra-fine HAp particles were obtained without additional thermal treatment. The TEM micrograph (Fig. 2a) shows the ball-like structure of as-synthesized $\sim 10 \mathrm{~nm}$ HAp crystal. Because of the high surface energy, ultra-fine particles are easily self-aligned in spherical aggregates approximately $100 \mathrm{~nm}$ in diameter, as shown in Fig. 2b. Therefore, the thermal treatment facilitates the aggregation and finally results in the growth of HAP from ultra-fine crystal to large particle. The raw HAp powder is calcium deficient and carbonate free (See the later FTIR spectrum) with the $\mathrm{Ca} / \mathrm{P}$ ratio of 1.55 .

\subsection{Shrinkage of green compacts}

Although the solvent in the suspension is partially removed during the $\mathrm{CIC}$ process, the green compact after CIC process is still solvent-containing. The compact tends to shrink via evaporation of residual solvent during drying. The relationship between linear shrinkage (Ls) and drying time (Fig. 3) shows that shrinkage mainly occurs within $30 \mathrm{~h}$, often which remains constant at about $30 \%$.

\subsection{Relative density and microstructure of HAp ceramics}

A SEM observation of the fractured surface of $77.8 \%$ dense HAp ceramic sintered at $1100{ }^{\circ} \mathrm{C}$ is shown in Fig. 4 . The average grain size of HAp markedly increases from $\sim 10 \mathrm{~nm}$ of the precursor to $\sim 1 \mu \mathrm{m}$ at $1100{ }^{\circ} \mathrm{C}$

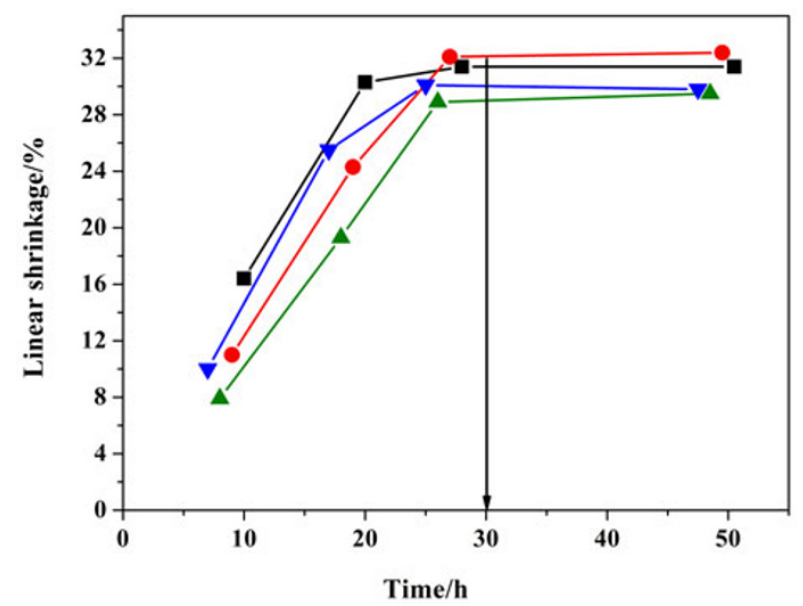

Fig. 3 Relationship between linear shrinkage and drying time of green compacts (four samples) 

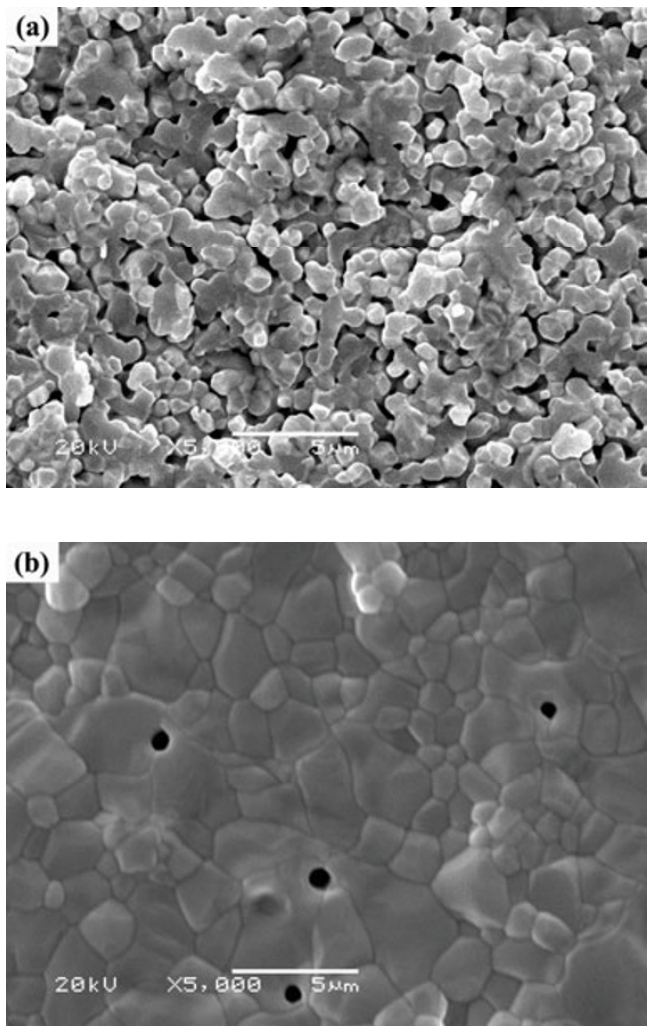

Fig. 4 SEM micrographs of cross-sectionals: (a) HAp ceramic sintered at $1100{ }^{\circ} \mathrm{C}$, (b) HAp ceramic sintered at $1200{ }^{\circ} \mathrm{C}$

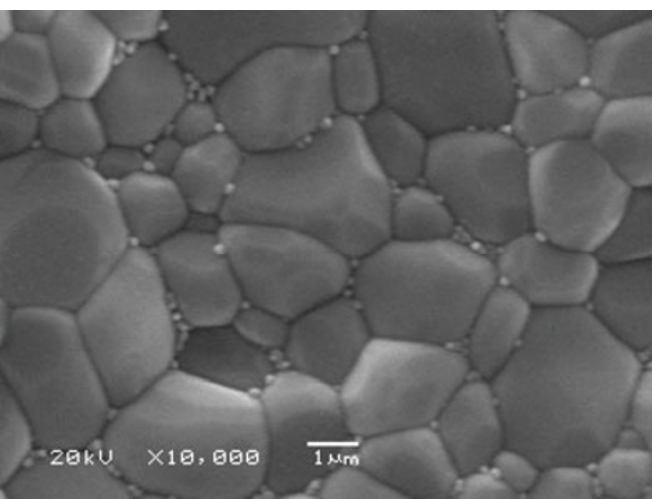

Fig. 5 SEM micrographs of the outermost surface for HAp ceramics sintered at $1200{ }^{\circ} \mathrm{C}$

(Fig. 4a) and several micrometers at $1200{ }^{\circ} \mathrm{C}{ }^{\circ} \mathrm{C}$ (Fig. 4b). The $94.1 \%$ dense sample sintered at $1200{ }^{\circ} \mathrm{C}$ shows nearly equiaxed uniform microstructure except for a few spherical pores on the boundary of the HAp grains.

SEM micrograph of Fig. 5 reveals different microstructures on the outermost surface and the fractured surface of HAp ceramic sintered at $1200{ }^{\circ} \mathrm{C}$ consisting of some small spherical particles $(12-13 \mathrm{~nm}$ in diameter) at grain boundaries and triple points.

\subsection{Decomposition mechanism of HAp ceramic}

It can be observed that ultra-fine HAp precursor is single phase and highly crystallized (Fig. 6a) and all peaks corresponded with HAp based on the standard XRD pattern of HAp (JCPDS card no. 09-432). XRD analysis of sample sintered at $1100{ }^{\circ} \mathrm{C}$ and $1200{ }^{\circ} \mathrm{C}$ reveals the presence of a small amount of $\alpha$-TCP phase $(\alpha$-tricalcium phosphate marked with $\bullet$ in Figs. $6 \mathrm{~b}$ and c), which derived from decomposition of HAp ceramic at $1200{ }^{\circ} \mathrm{C}$. Therefore, those small particles at grain boundaries and triple points on the outermost surface of HAp ceramic in Fig. 5 are the decomposition product $(\alpha-\mathrm{TCP})$ of HAp because of high reaction activity on grain boundary. The decomposition of HAp begins from the outside of the ceramic body at $1200{ }^{\circ} \mathrm{C}$ and the decomposition product appears only on the surface of the ceramic body.

Fig. 7 shows the FT-IR spectra of ultra-fine HAp powder and the samples sintered at $1100{ }^{\circ} \mathrm{C}$ and $1200{ }^{\circ} \mathrm{C}$. In Fig. 7a, the hydroxyl stretching bands and bending bands of HAp are assigned respectively at $3569 \mathrm{~cm}^{-1}$ and $632 \mathrm{~cm}^{-1}$, while the broad band at $3414 \mathrm{~cm}^{-1}$ corresponds to the absorbed water. The adsorptions at $1095,1035,962,603$, and $566 \mathrm{~cm}^{-1}$ are attributed to $\mathrm{PO}_{4}^{3-}$ ions $\left(v_{1}-962 \mathrm{~cm}^{-1}, v_{3}-1035 \mathrm{~cm}^{-1}\right.$ and $1095 \mathrm{~cm}^{-1}, v_{4}-566 \mathrm{~cm}^{-1}$ and $\left.603 \mathrm{~cm}^{-1}\right)[19,20]$. The

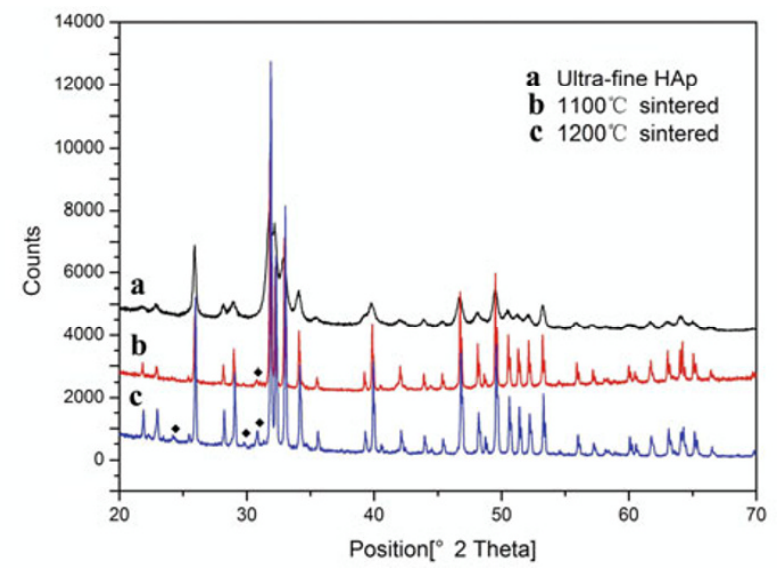

Fig. 6 XRD patterns of (a) ultra-fine HAp powder, (b) and (c) HAp ceramics sintered at $1100^{\circ} \mathrm{C}$ and $1200^{\circ} \mathrm{C}$ for $4 \mathrm{~h}$, respectively. $\bullet$ peaks correspond to $\alpha$-tricalcium phosphate (JCPDS card no. 09-348), all the other peaks correspond to hydroxyapatite based on the standard XRD pattern card of HAp (JCPDS card no. 09-432) 


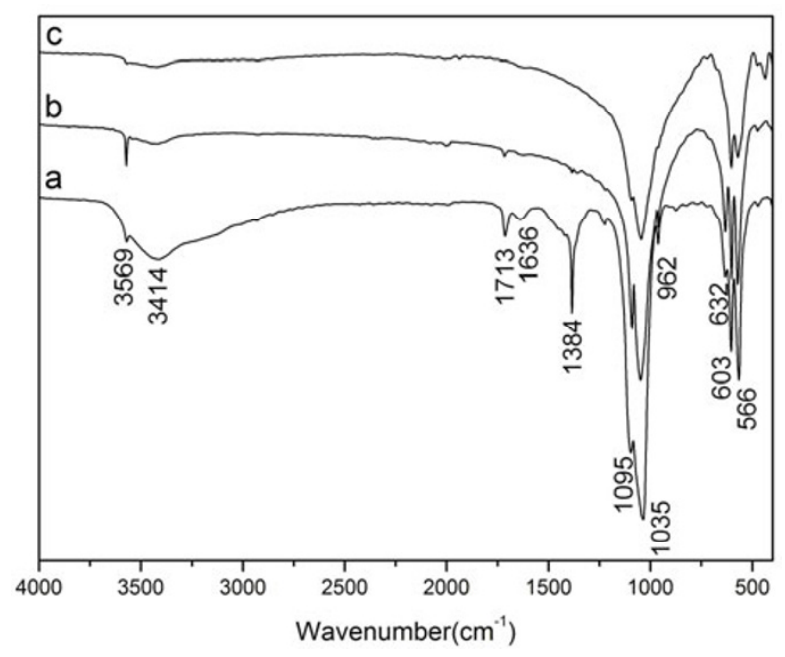

Fig. 7 FT-IR spectra of HAp samples: (a) ultra-fine HAp powder; (b) and (c) HAp ceramic sintered at $1100{ }^{\circ} \mathrm{C}$ and $1200{ }^{\circ} \mathrm{C}$, respectively

broad band at $3211 \mathrm{~cm}^{-1}$ and the adsorption at $1384 \mathrm{~cm}^{-1}$ are originated from $\mathrm{NH}_{4}^{+}$on the surface of HAp crystal, which will decompose at high temperature. In Fig. 7, the intense band of hydroxyl group blueshift from $3569 \mathrm{~cm}^{-1}$ to $3572 \mathrm{~cm}^{-1}$, along with increase of intensity. Fig. 7c shows that the bands at $3572 \mathrm{~cm}^{-1}$ and $632 \mathrm{~cm}^{-1}$ disappear completely at a sample temperature of $1200{ }^{\circ} \mathrm{C}$, which indicates the dehydration of $\mathrm{OH}$ group at $1200{ }^{\circ} \mathrm{C}$.

The decomposition mechanism is proposed on the basis of above experimental results. The decomposition of HAp begins from dehydration of $\mathrm{OH}$ group at $1200{ }^{\circ} \mathrm{C}$, which results in the formation of intermediate (oxyapatite). The dehydration occurs according to the following reactions $[21,22]$ :

$$
\begin{gathered}
2 \mathrm{OH} \rightarrow \mathrm{O}+\mathrm{H}_{2} \mathrm{O}(\mathrm{g}) \\
\mathrm{Ca}_{10}\left(\mathrm{PO}_{4}\right)_{6}(\mathrm{OH})_{2} \rightarrow \mathrm{Ca}_{10}\left(\mathrm{PO}_{4}\right)_{6} \mathrm{O} \cdot+\mathrm{H}_{2} \mathrm{O}(\mathrm{g})
\end{gathered}
$$

The $\square$ means a non-charged vacancy and the hydroxyl-deficient product $\mathrm{Ca}_{10}\left(\mathrm{PO}_{4}\right)_{6} \mathrm{O} \bullet \square$ is known as oxyapatite. Further decomposition of HAp will result in the formation of tricalcium phosphate (TCP phase).

In this study, high temperature $\left(1200{ }^{\circ} \mathrm{C}\right)$ leads to decomposition of HAp ceramic to $\alpha$-TCP (Figs. $6 \mathrm{~b}$ and $6 c)$. Because of high activity on the verges of HAp grains, the decomposition firstly begins from the crystal verge. Therefore, the decomposed product (small spherical particle) was usually found on the grain boundary at the surface of sintered body (Figs. 5a and $5 b)$. However, it should be noted that the transformation of HAp to $\alpha$-TCP phase is rather limited in this work.

\section{Conclusion}

Through CIC process and pressureless sintering, highly densified HAp ceramics is prepared from ultra-fine spherical particles precursor. Sintering temperature is vital for the densification and grain sizes of HAp ceramics. At $1200{ }^{\circ} \mathrm{C}$, nearly equiaxed uniform microstructure could be obtained. However, high temperature simultaneously results in the formation of larger grains and decomposition of HAp crystal.

Open Access This article is distributed under the terms of the Creative Commons Attribution License which permits any use, distribution, and reproduction in any medium, provided the original author(s) and source are credited.

\section{Acknowledgement}

The authors acknowledge the financial support for this work from China-Ukraine Inter-governmental S\&T Cooperation by Ministry of Science and Technology of China (CU08-15).

\section{References}

[1] Afshar A, Ghorbani M, Ehsani N, et al. Some important factors in the wet precipitation process of hydroxyapatite. Mater design 2003, 24: 197-202.

[2] Riman RE, Suchaned WL, Byrappa K, et al. Solution synthesis of hydroxyapatite designer particulates. Solid State Ionics 2002, 151: 393-402.

[3] Ahn ES, Gleason NJ, Nakahira A, et al. Nanostructure processing of hydroxyapatite-based bioceramics. Nano Lett 2001, 1: 149-153.

[4] Rodriguez-Lorenzo LM, Vallet-Regi M, Ferreira JMF. Fabrication of hydroxyapatite bodies by uniaxial pressing from a precipitated powder. Biomater 2001, 22: 583-588.

[5] Han YC, Li SP, Wang XY, et al. Synthesis and sintering of nanocrystalline hydroxyapatite powders 
by citric acid sol-gel combustion method. Mater Res Bull 2004, 39: 25-32.

[6] Kumar R, Prakash KH, Cheang P, et al. Temperature driven morphological changes of chemically precipitated hydroxyapatite nanoparticles. Langm 2004, 20: 5196-5200.

[7] Kim HW, Koh YH, Li LH, et al. Hydroxyapatite coating on titanium substrate with titania buffer layer processed by sol-gel method. Biomat 2004, 25: 2533-2538.

[8] Liu HS, Chin TS, Lai LS, et al. Hydroxyapatite synthesized by a simplified hydrothermal method. Ceram Int 1997, 23: 19-25.

[9] Ioku K, Yamauchi S, Fujimori H, et al. Hydrothermal preparation of fibrous apatite and apatite sheet. Solid State Ion 2002, 151: 147-150.

[10] Liu DM, Yang QZ, Troczynski T. Water-based sol-gel synthesis of hydroxyapatite: process development. Biomat 2002, 23: 691-698.

[11] Kim TS, Kumta PN. Sol-gel synthesis and characterization of nanostructured hydroxyapatite powder. Mater Sci Eng B 2004, 111: 232-236.

[12] Yeong KCB, Wang J, Ng SC. Mechanochemical synthesis of nanocrystalline hydroxyapatite from $\mathrm{CaO}$ and $\mathrm{CaHPO}_{4}$. Biomat 2001, 22: 2705-2712.

[13] Mochales C, Briak-Benabdeslam HE, Ginebra MP, et al. Dry mechanochemical synthesis of hydroxyapatites from DCPD and $\mathrm{CaO}$ : Influence of instrumental parameters on the reaction kinetics. Biomat 2004, 25: 1151-1158.

[14] Rao PG, Iwasa M, Tanaka T, et al. Centrifugal casting of $\mathrm{Al}_{2} \mathrm{O}_{3}-15 \mathrm{wt} . \% \mathrm{ZrO}_{2}$ ceramic composites. Ceram inter 2003, 29: 209-212.

[15] Gao GW, Wang CY. Modeling the solidification of functionally graded materials by centrifugal casting. Mater Sci Eng A 2000, 292: 207-215.

[16] Rapacz-Kmita A, Paluszkiewicz C, Ślósarczyk A, et al. FTIR and XRD investigations on the thermal stability of hydroxyapatite during hot pressing and pressureless sintering processes. J Mol Struct 2005, 744-747: 653-656.

[17] Ooi CY, Hamdi M, Ramesh S. Properties of hydroxyapatite produced by annealing of bovine bone. Ceram Inter 2007, 33: 1171-1177.

[18] He ZM, Ma J, Wang C. Constitutive modeling of the densification and the grain growth of hydroxyapatite ceramics. Biomater 2005, 26: 1613-1621.

[19] Carmona P, Garcia-Ramos JV. Polarizable proton-transfer hydrogen bonds between phosphate and organic acids. J Chem Soc Farad Trans 2 1985, 81: 929-935.

[20] Gonzalez-McQuire R, Chane-Ching JY, Vignaud E, et al. Synthesis and characterization of amino acid-functionalized hydroxyapatite nanorods. $J$ Mater Chem 2004, 14: 2277-2281.

[21] Liao CJ, Lin FH, Chen KS, et al. Thermal decomposition and reconstitution of hydroxyapatite in air atmosphere. Biomater 1999, 20: 1807-1813.

[22] Muralithran G, Ramesh S. The effects of sintering temperature on the properties of hydroxyapatite. Ceram Inter 2000, 26: 221-230. 